\title{
A POST-ANAESTHETIC FOLLOW-UP PROGRAM
}

\author{
Maureen Burnham and Douglas B. Craig
}

\begin{abstract}
Experience with an in-hospital post-anaesthetic follow-up program is reported. Visits are made by a Registered Nurse, a hospital employee working under the direction of the Head of the Department of Anesthesia. Over a three-year period 21,116 of 39.239 patients receiving anaesthetics were visited. Those not visited were mainly outpatients or patients discharged early following minor surgery. Anaesthetic related minor complications were noted in 8.15 per cent of the patients seen in follow-up. Major complications occurred in 0.37 per cent of patients seen.
\end{abstract}

WHAT IS THE ANAESTHETIST'S RESPONSIBILITY for the late post-anaesthetic follow-up? While most would agree that post-anaesthetic visits are desirable, various factors make routine visits impractical. Most obvious, in a time of anaesthesia manpower shortage, is the lack of available time in the working day already extended by long operating lists, followed by pre-anaesthetic visits for the following day. Another negative influence is the observation that in that large majority of patients who have had uneventful anaesthetics, very few new and important anaesthetic-related findings become apparent for the first time in the late post-anaesthetic period. Most anaesthetists therefore reserve post-anaesthetic visits for known high-risk patients and for patients in whom complications were observed during the anaesthetic or the early recovery period, or in whom presumed anaesthetic-related complications have been reported to be present in the late recovery period.

Although the 1972 "Guide to Hospital Accreditation"' of the Canadian Council on Hospital Accreditation refers to post-anaesthetic visits, the more recent 1977 edition does not. The 1972 section on 'Anaesthetic Services' includes the notation: "Written medical staff policies relative to anaesthesia care should include provision for at least the recording of post-anaesthetic visits that include at least one note describing the pres-

Maureen Burnham, R.N., Post-Anesthetic Follow-up Nurse, Department of Anaesthesia, Health Sciences Centre, Winnipeg, Manitoba; Douglas B. Craig, M.D., F.R.C.P.(C), Professor, Department of Anaesthesia, University of Manitoba.

Reprint Requests to: Douglas B. Craig, M.D., Department of Anaesthesia, Health Sciences Centre, A709, Winnipeg, Manitoba, Canada, R3E 023. ence or absence of anaesthetic-related complications". The "Guidelines for the minimal Standards of Practice of Anaesthesia" "2, published by the Canadian Anaesthetists' Society include recommendations for both the early (recovery room) and later phases of the post-anaesthetic period. With respect to the later phase the guidelines state: "Although a post-anaesthetic visit is desirable, it is not mandatory and should be left to the discretion of the anaesthetist."

This report describes our experience with a program which we have found to be a very satisfactory and practical solution to the overall problem of post-anaesthetic follow-up. Although the program has been in operation for almost ten years, we are reporting only our more recent experience for the three complete years 1976, 1977 and 1978.

The program operates within the hospital Department of Anaesthesia (as distinguished from the University Department, or attachment to the private medical practice component of the Department). Post-anaesthetic visits are conducted by a Registered Nurse, with supplemental visits by physician department members, as will be described. A computer-based information retrieval system and an associated specially designed anaesthetic record are essential components of the program.

The post-anaesthetic follow-up nurse is a hospital employee, working under the supervision of the Head of the Department of Anaesthesia. She visits all adult patients who have received any form of anaesthetic administered by members of the department, with the exception of obstetrical patients, for whom a separate follow-up program exists.

Except for patients who have had major

Canad. Anaesth. Soc. J., vol. 27, no. 2, March 1980 


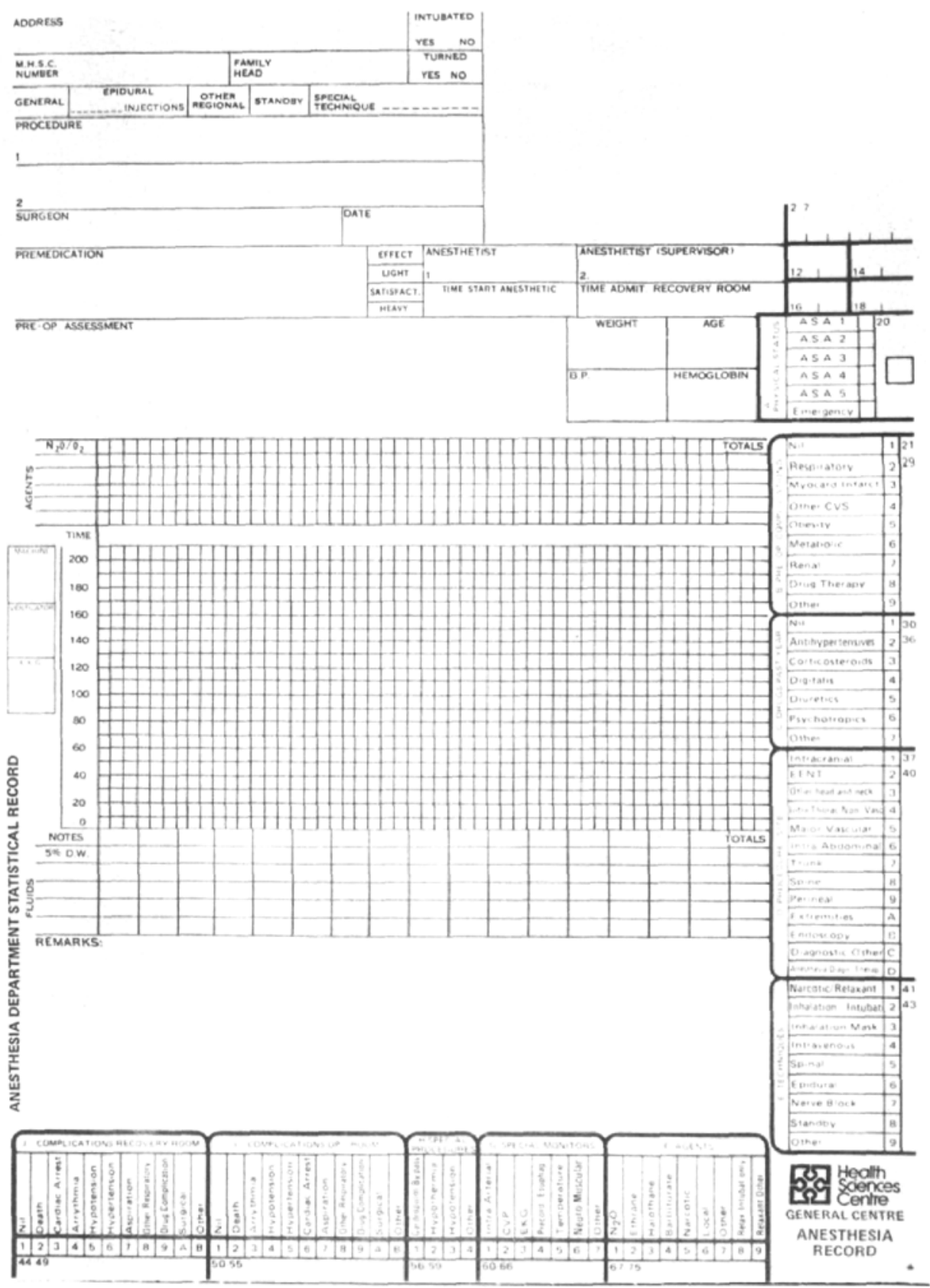

FIGURE 1

surgery, where a delay of several days is allowed, (Figure 1). When completed, this record contains the visit normally occurs on the day following the summary information about the pre-anaesthetic, anaesthetic. The follow-up nurse receives daily a anaesthetic and recovery room periods in coded copy of the anaesthetic record for all patients andalso in narrative form. Details of the course of 


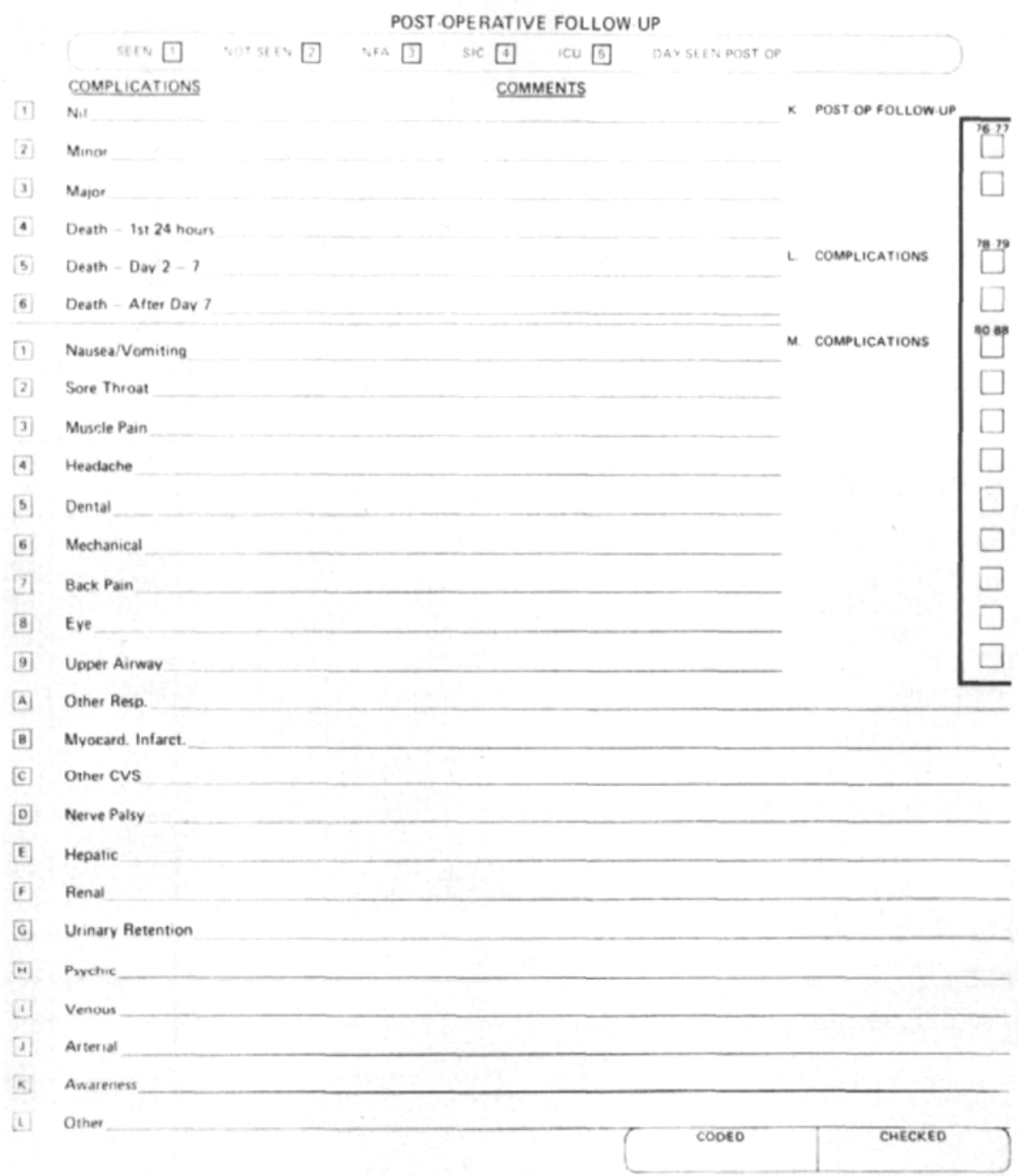

FiguRE 2

anaesthesia, including any problems or complications, will also be recorded.

With this information available, the follow-up nurse then conducts the post-anaesthetic visit. First a chart review is done, including a review of the recovery room record and those components of the chart which note the general condition of the patient. If specific problems had been encountered earlier, or are expected (e.g. cardiac arrhythmias), a special search is made for relevant information.
The patient is then interviewed, with an attempt being made by the follow-up nurse to identify complaints and problems related to the anaesthetic. Frequently a judgment must be made, based on experience and the information on hand, to distinguish anaesthetic-related problems from others.

The back of the departmental copy of the anaesthetic record (Figure 2) is used by the follow-up nurse to record the results of the postanaesthetic visit. Complications are classified as 
TABLE I

Post-ANAesthetic Follow-UP

SUMMARY OF EXPERIENCE

\begin{tabular}{lcccc}
\hline \hline & 1976 & 1977 & 1978 & Total \\
\hline Patients receiving anaesthetics & 12775 & 13051 & 13413 & 39239 \\
Patients seen following anaesthesia & 6764 & 7093 & 7259 & 21116 \\
Problems and complications & & & & \\
Minor & 645 & 572 & 505 & 1722 \\
Percentage of paticnts seen & 9.54 & 8.06 & 6.96 & 8.15 \\
Major & 27 & 39 & 13 & 79 \\
Percentage of patients seen & 0.40 & 0.55 & 0.18 & 0.37 \\
Nausea and vomiting & & & & \\
Sore throat & 395 & 360 & 326 & 1081 \\
Muscle pain & 141 & 76 & 71 & 288 \\
Headache & 22 & 27 & 15 & 64 \\
Dental & 20 & 26 & 13 & 59 \\
Mechanical & 6 & 7 & 9 & 22 \\
Back pain & 36 & 26 & 15 & 77 \\
Eye & 6 & 2 & 2 & 10 \\
Respiratory & 2 & 7 & 3 & 12 \\
Myocardial infarction & 5 & 9 & 6 & 9 \\
Other cardiovascular & 4 & 4 & 1 & 83 \\
Nerve palsy & 26 & 29 & 28 & 10 \\
Psychic & 2 & 3 & 5 & 17 \\
Venous & 4 & 2 & 11 & 15 \\
Arterial & 5 & 4 & 13 & 44 \\
Other & 17 & 14 & & \\
\hline & & & & \\
\hline
\end{tabular}

'major' if they affect the welfare of the patient by being a threat to the patient's life, prolonging the hospital course, or otherwise affecting the outcome of the hospitalization. "Minor" complications are more in the nature of discomfort or inconvenience, without the above features.

In the absence of complications which are viewed by the follow-up nurse as requiring the anaesthetist's attention, the completed anaesthetic record is returned to the anaesthetist for later review. If the follow-up nurse encounters any problems or complications which she considers require the anaesthetist's attention, she immediately brings these to the individual's attention by direct communication. In this case, it is the anaesthetist's responsibility to visit the patient himself and to take whatever action he feels to be appropriate.

When the anaesthetist has reviewed the completed record, it is transferred to our information retrieval system. Coded data on both sides of the anaesthetic record are read directly by key-punch operators, and transferred to tapes. The closing date for information input is the 10th working day of each following month, with the departmental summary returned one week later. An annual summary is provided on a calendar year basis.

Table I summarizes our recent experience with the program. There were an average of approximately 7,000 visits per year, requiring the fulltime efforts of the follow-up nurse. The difference between the total number of patients receiving anesthetics and those seen in follow-up represents mainly out-patients and those who were discharged early following operation, before the follow-up nurse had an opportunity to visit. Table I summarizes the complications noted and indicates that, over the three years, a mean of 8.15 per cent of those patients seen had problems or complications which were thought to be related to the anaesthetic. Serious complications occurred in less than 0.4 per cent of patients seen in follow-up. It is important to appreciate that the incidence of problems or complications in the overall patient population, including those who were not seen as well as those who were seen, is unlikely to be the same as in the group which was seen. This is because the group that was not seen was, for the most part, those who had less major operations, shorter anaesthetics and, therefore, earlier discharge from hospital. A lower overall incidence is likely.

What are the benefits of our follow-up program? First it provides an effective mechanism for accommodating our view that post-anaesthetic follow-up is a necessary and important part 
of anaesthetic care. This accommodation is achieved in a time-effective manner, reserving the input of the anaesthetist to those situations where it is truly required. There are however considerable additional benefits to the program, in the categories of audit, service, and research. Our follow-up nurse is a valuable member of the Departmental Standards Committee, which has the responsibility for monitoring the quality of care within the Department. An example of an ongoing service program is the family follow-up of patients found to have atypical cholinesterase. A registry of patients and their families is kept in the Department of Anaesthesia. Research ac- tivities have included a study correlating the findings of "routine" pre-anaesthetic electrocardiograms with the intra-operative and postoperative course.

We hope that others will be encouraged by our positive experience to construct their own follow-up programs.

\section{REFERENCES}

1. Guide to Hospital Accreditation, 1972. Canadian Council on Hospital Accreditation, Toronto.

2. Guidelines for the Minimal Standards of Practice of Anaesthesia. Canadian Anaesthetists' Society, Toronto (1977).

\section{RÉSUMÉ}

Les auteurs décrivent leur expérience dans l'application d'un programme hospitalier de surveillance des suites post-anesthésiques. Les visites furent effectuées par une infirmière licenciée employée par l'hôpital et sous l'autorité du chef du département d'anesthésie. Sur une période de trois ans, 21,116 patients anesthésiés sur un total possible de 39,239 ont été visités.

Le groupe exclu était constitué de malades ambulatoires ou libérés précocement après une intervention mineure. On a noté des complications mineures en rapport avecl'anesthésie dans 8. 15 pour cent des cas et des complications majeures dans 0.35 pour cent 